\title{
Causes of and Remedies for Chinglish in Chinese College Students’ Writings
}

\author{
Ping Wang ${ }^{1}$, Weiping Wang ${ }^{2}$ \\ ${ }^{1}$ School of Foreign Languages and Literature, Wuhan University, Wuhan, China \\ ${ }^{2}$ Foreign Language Department, Huazhong University of Science and Technology, Wuhan, China \\ Email: Wangping1013@126.com
}

Received March 19 $9^{\text {th }}, 2012$; revised May $2^{\text {nd }}, 2012$; accepted May $9^{\text {th }}, 2012$

\begin{abstract}
Based on Interlanguage Theory and other theories, this study examines data from samples of Chinese college students' writings and interviews with the students to explore the causes of and remedies for Chinglish (a term used to refer English with Chinese characteristics). It claims that Chinglish is mainly caused by syntactic transfer from Chinese, the influence of Chinese thought patterns, inadequate exposure to authentic English and insufficient practice in English writing. The interviews with the students showed that the proportion of L1 thinking decreased with the writer's L2 development. The recommended remedies for Chinglish include raising students' awareness of distinctions between English and Chinese, increasing their exposure to authentic English and practice in English writing, and adjusting their thought patterns.
\end{abstract}

Keywords: Chinglish; ESL Writing; Causes; Remedies

\section{Introduction}

Much research concerning the nature and sources of Chinglish has been done in the writings of Chinese ESL learners in light of interlingual theory, contrastive analysis, error analysis, and language transfer theory. Some scholars regard negative transfer from Chinese as the main cause of Chinglish (e.g. Ellis, 1985; Odlin, 2001; Li, 2007; Yu, 2004); others attribute production of Chinglish to allegedly different thought patterns of Chinese and westerners (e.g. Cook, 1991; Jia, 1997; Lian, 2002; Wang \& Wen, 2002). One hypothesis is that contrastive analysis can help L2 learners reduce interference from the first language and produce more target language-like English by becoming aware of the differences between the two languages. From a perspective of contrastive analysis, this paper analyzes some differences between English and Chinese languages and the influences of Chinese language, culture, and thought patterns in an attempt to reveal some causes of and remedies for Chinglish. This is done by analyzing examples from Chinese college students' writings and data from interviews with the students. To that end, I will focus on dissimilarities rather than similarities between the English and Chinese languages and cultures, and on the negative impact of $\mathrm{L} 1$ rather than its positive one. Also, this paper is written both with the hope of providing EFL and ESL teachers with suggestions to help Chinese students avoid Chinglish and produce authentic English, and contributing to the theory and practice of second language pedagogy in writing instruction.

What is Chinglish? Pinkham (1998) defines Chinglish as "English with Chinese characteristics” (p. 1). Deng (2001) defines it as "speech or writing in English that shows the interference or influence of Chinese" (p. 106). Chinglish is nonidiomatic English which is produced by Chinese learners who draw upon Chinese structure and culture as a result of mother tongue interference or influence; it is a term commonly used to describe the mixture of Chinese and English. Chinglish as discussed in this paper is mainly an issue of appropriateness of language use rather than correctness because all the so-called Chinglish examples are actually grammatically correct, as in the example "He was very excited and he couldn't speak a word." However, it is not as idiomatic as "He was too excited to speak a word." or "He was so excited that he couldn't speak a word.”

\section{Theoretical Perspective}

Chinglish is closely related to interlanguage. "Interlanguage" is defined as "language learner language" by Ellis (1985) and "learner variety” by Klein (1986). Ellis (2000) recognizes the fact that a learner constructs a linguistic system that draws, in part, on his/her L1 but is also different from it and also from the target language. A learner's interlanguage is, therefore, a unique linguistic system (p. 33).

Ellis (2000) further puts forward the following computational model of L2 acquisition:

input $\rightarrow$ intake $\rightarrow$ L2 knowledge $\rightarrow$ output

This model suggests that the human mind functions like a computer. It represents the basic computational metaphor that has grown out of "interlanguage" and that informs much of L2 acquisition. To Ellis (2000), the learner is exposed to input, which is processed in two stages. First, parts of it are attended to and taken into short-term memory. They are referred to as intake. Second, some of the intake is stored in long-term memory as L2 knowledge. The processes responsible for creating intake and L2 knowledge occur within the 'black box' of the learner's mind where the learner's interlanguage is constructed. Finally, L2 knowledge is used by the learner to produce spoken and written output (p. 35). Ellis' (2000) model provides an understanding about how language learning takes place.

Under the general rubric of interlanguage studies, several 
theories that address some critical features of L2 acquisition are considered to be underlying the causes of and remedies for Chinglish in this paper. They are: Language Transfer Theory, Krashen's (1985) Comprehensible Input Hypothesis, Swain's (1985) Output Hypothesis, Schmidt's (1990) Noticing Hypothesis, and Long's (1996) Interaction Hypothesis. One of the factors influencing the production of Chinglish is L1 language transfer, in which learners' previously acquired knowledge influence the outcome of their later learning or training behaviors. Ellis (2000) recognizes that learners have perceptions regarding the linguistic features of their own language. They treat some features as potentially transferable and others as potentially non-transferable and they are more prepared to risk transferring the features than they are those they perceive to be unique to their own language (p. 53). Negative transfer usually occurs where there are substantial or subtle differences between learners' L1 and L2.

Krashen's (1985) Comprehensible Input Hypothesis claims that adequate exposure to the target language is necessary for language development, whereas Swain's (1985) Output Hypothesis argues that in addition to input, output production of the targeted form is needed for learners to properly internalize grammatical structures. Schmidt's (1990) Noticing Hypothesis contends that it is only when learners have noticed their errors that the correct form can be retained in their memory. Long's (1996) Interaction Hypothesis states that negotiation between the teacher and the learner is essential for successful learning.

Language transfer is one of the main causes of Chinglish. The Input and Output Hypotheses help to recognize other causes of Chinglish in Chinese college students' writings: their inadequate exposure to authentic English and insufficient practice in writing English. The Noticing and Interaction Hypotheses help to find remedies for Chinglish by calling students' attention to crosslinguistic differences and enhancing teacherstudent and peer interaction.

\section{Methodology}

In order to determine the causes of and remedies for Chinglish, this study gives a detailed analysis of examples of Chinglish from samples of Chinese college students' writings, and data from interviews with these students. Written data were collected as follows: After each session of a writing class where process writing was used in writing instruction, students were assigned to write bi-weekly composition on such topics as "How to avoid misunderstanding" and "My Understanding of Winning". The examples were collected in 2011 from the writing assignments of the 58 first-year college students (28 males and 30 females) from Wuhan University, China, all being nonEnglish majors with an average age of 19. Their English placement test scores ranged from 67 - 93 (on a scale of 100), showing variations in their English proficiency. Before college, the students had learned English in a systematic way for more than four hours a week for six or more years including basic knowledge in grammar and basic skills in listening, speaking, reading, writing and translation. However, a considerable amount of exposure and practice is required for Chinese college students to improve English proficiency and produce more target language-like English. Apart from their writing assignments, the 58 first-year college students were interviewed one week after the data collection on their writing processes and their ways of thinking when they wrote in English, including their interpreta- tion of the writing topic, pre-writing thinking, outline writing, actual writing and writing process regulation (e.g. timing, meeting the length of the writing, etc.). The interviews were held during the 10-minutes break with approximately 5 minutes for each interviewee over the course of about 3 months (see appendix for the interview questions).

\section{Causes and Remedies for Chinglish}

\section{Syntactic Transfer from Chinese}

Contrastive analysis theory assumes a kind of competence model in which one set of knowledge (the learner's first language) comes into contact through the learning process with a second set of knowledge (the target language). Where the two structures match, learning is easy; where they differ (in form or use), a difficulty arises that needs to be overcome (Spolsky, 2000: p. 117). Chinglish is caused partly by student's unawareness of the syntactic distinctions between English and Chinese.

English and Chinese belong to different language systems. English is subject-prominent (Xiao \& Li, 2007: p. 79), S-V complex (main subject + main verb + sub-structures) are primary in English; Chinese is topic-prominent (Xiao \& Li, 2007: p. 79), and Chinese sentences do not necessarily match the S-V structure. English sentences are mostly hypotactic (emphasizing the S-V structure) and compact, whereas Chinese sentences are mostly paratactic (emphasizing meaning and function rather than the S-V structure) and diffusive (Lian, 1993: p. 48). English sentences demonstrate an "architecture style" in which various sub-structures cluster around the basic S-V structure just like a building with a basic structure; in contrast, Chinese sentences exhibit a "chronicle style" in which word order tends to represent temporal sequences or logic relationships. English and Chinese also differ in inflection and in the frequency of the use of cohesive ties. English relies on a large number of prepositions and conjunctives to express grammatical meaning. S-V complex and abundant cohesive ties in English makes it possible for English sentences to extend in length and yet remain precise and compact in both form and meaning. The linguistic distinctions between English and Chinese at the formal level can be classified in the Table $\mathbf{1}$.

English sentences are characterized by S-V structure, compactness, and more complex sentences; in contrast, Chinese sentences are characterized by diffusiveness and more simple clauses. A comparison between an English sentence and its Chinese counterpart will illustrate the syntactic distinctions between English and Chinese: "It is deeply rooted prejudice to think that innovation constitutes a great threat to social harmony and unity because technological progress has been indeed destroying many employment opportunities and therefore bringing misery to thousands of people for hundreds of years."

Table 1.

Linguistic distinctions between English and Chinese.

\begin{tabular}{ll}
\hline English & Chinese \\
\hline more S-V complex sentences & less S-V structure \\
compact & diffusive \\
architecture style & chronicle style \\
hypotactic & paratactic \\
abundant cohesive ties & fewer cohesive ties \\
more complex sentences & more simple clauses \\
\hline
\end{tabular}


The Chinese counterpart is “这是一个根深蒂固的偏见:即认 为革新对社会的和谐统一构成很大的威胁。因为几百年来, 技术进步的确破坏了许多就业机会, 因而给成千上万的人带 来了苦难。” The main structure of the English sentence is “It is a prejudice to think that ... because..." in which "it" is the subject and "is" is the main verb of the sentence, and the preposition "to" and modifier "because" help to link clauses and make the sentence compact. The Chinese sentence is more diffusive as it contains five clauses.

Chinese students who are not in an authentic English environment usually ignore the syntactic distinctions between English and Chinese. They think in Chinese and then translate what they think into English without consideration of English syntax. In the Chinese-English transference process, the thinking process is from meaning and function to form, and the result is Chinglish: English with Chinese characteristics. It suggests negative transfer of Chinese syntax to English. The following pairs of sentences show Chinese college students' transference of Chinese syntax due to lack of knowledge of English syntax. (The examples of Chinglish in the "a" versions are taken from samples of students' writings, and the examples in the "b" versions are revised sentences after discussions between the teacher and the students.)

(1) a) My hometown is Xianghuan City. It has ancient walls. The walls are built all around the city. My hometown is not a big city, but it has a long history and its unusual beautiful scenery.

b) My hometown, Xianghuan, is a city with ancient walls all around it. Although, not big, it has a long history and unusual scenic beauty.

Thirty-five words and 4full sentences in (1a) convey the meaning of the sentence; it is more diffusive in structure than (1b), which consists of 24 words and 2 full sentences. The noun phrases "my hometown" and "the wall" are repeated in (1a), whereas there is no repetition of nouns in (1b), resulting in the sentence's compactness. Sentences (1a) is a word-for-word translation of the Chinese sentence, which is due to the student's thinking-in-Chinese-and-translating-into-English" strategy. The interviews showed that some students adopted this strategy in their English writings.

(2) a) We get all the norms in the process of our growing up, and just like the languages we speak and the beliefs we accept, they have become a part of our culture.

b) All the norms are acquired by all of us in the course of our growing up and are as much a part of our culture as the languages we speak or the beliefs we accept.

(2b) is a typical English sentence characterized by a S-V structure or a stem-branches-leaves sequence. The stem in (2b) is "all the norms"; the two branches are "are acquired by all of us" and "are as much a part of our culture"; and the leaves are "in the course of our growing up", "as the languages we speak", and "the beliefs we accept". (2a) is formed by three clauses, arranged according to the Chinese way of thinking. The three clauses are like three parallel lines. Thus, English sentences can be compared to giant trees with complicated branches and leaves, whereas Chinese sentences are compared to a square of waves pushing forward layer upon layer (see Diagram 1).

Chinese college students should be aware of the distinctions between English and Chinese syntax, and make the English sentences they write compact by arranging then in a S-V structure or stem-branches-leaves sequence. Zhang (2004) recommends
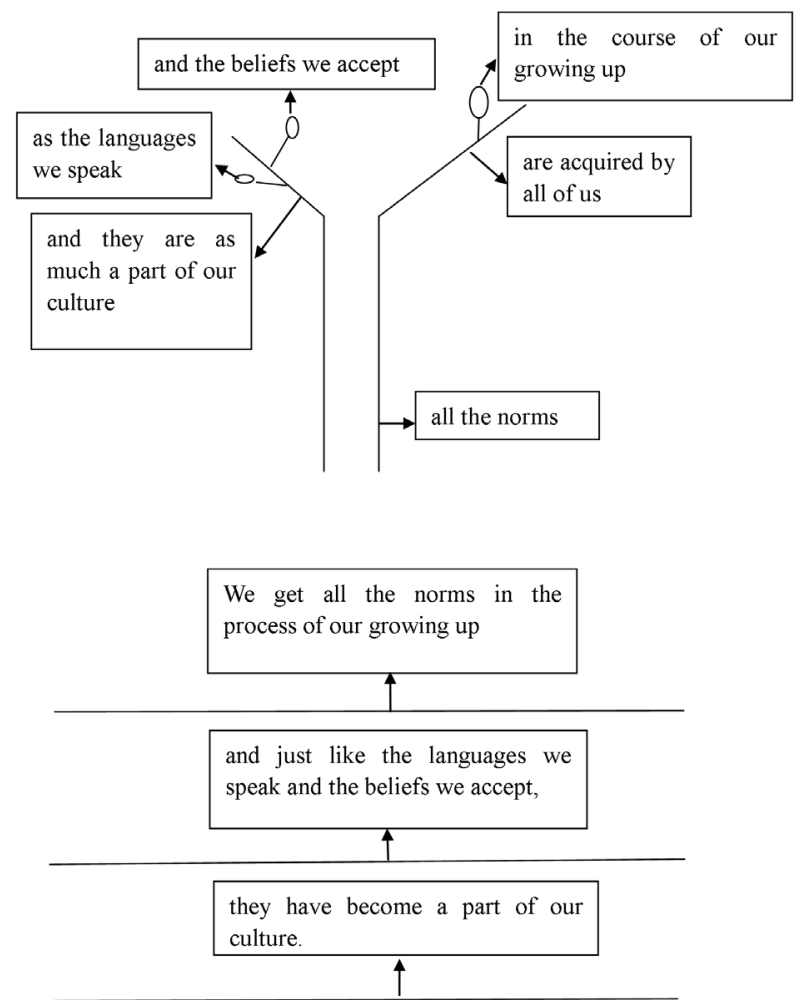

Diagram 1.

Distinction between the English and Chinese sentence structure.

an efficient way to avoid Chinglish when one lacks knowledge of English syntax: try to distil the semantic emphasis of the sentence, and then put it in English sentence structure (p. 58). Bao's (2001) ways of adjusting English sentences in translation is applicable to sentence adjustment in English writing: adjust the length of the sentence, the sentence structure, the semantic emphasis, and the ways of expression (pp. 35-50). Take (2) for example: The semantic emphasis of the sentence is "all the norms are acquired ... and are as much a part of our culture..." Once the semantic emphasis has been determined, it is easy to adjust the sentence according to English S-V structure.

The fundamental syntactic distinctions between English and Chinese should be introduced to Chinese students and they should be aware of them when they write an English composition. For example, Chinese students are likely to write the following sentence: "Humorous individuals are liked by people, they often become the focus of attention in any gathering. We have reasons to say these.” Teachers can ask students to make the sentence more target language-like by putting it in the typical English sentence structure "It is ... to... (that)...". A more target language-like sentence is: "It is reasonable to say that humorous individuals are not only well liked by people, but are often the focus of any gathering.” Apart from knowledge of the distinctions between English and Chinese syntax, it is helpful to practice using appropriate sentence structures sufficiently so as to "anchor it solidly in students' consciousness" (Spada \& Lightbown, 2008: p. 58). Izumi and Bigelow (2000) claim that more accurate use of linguistic forms can be produced when learners' attention is deliberately drawn to the targeted form via task manipulation. Teachers can ask students to make more English sentences by using typical English sentence structures 
such as "It is ... to... (that)...". For example, "It is a good approach to involve children in decision making because...". When the new linguistic pattern has been perceived, frequent production of the pattern will make it more and more retrievable.

The linguistic distinctions between English and Chinese hinder Chinese college students' production of target languagelike English. Raising students' awareness of the linguistic distinctions and practice of English sentence structure will help to reduce Chinglish caused by syntactic transfer from Chinese.

Apart from syntactic transfer from Chinese, other factors also contribute to Chinglish including differences in culture, thought patterns, comprehension processes, and students' learning strategies. Influence of the Chinese thought patterns is a typical cause of Chinglish for the Chinese college students.

\section{Influence of the Chinese Thought Patterns}

Researchers in contrastive rhetoric argue that certain culturally determined ways of thinking and communicating transfer themselves to second language texts (Nunan, 2001: pp. 296297). Jia (1997) found that the Chinese prefer circular thinking, whereas westerners prefer linear thinking. The following diagram (Figure 1) illustrate the different thought pattern between Chinese and westerners:

Circular thinking is characterized by a preference for indirectness or circumlocution, and is called inductive thinking or particular-general thinking, whereas linear thinking is characterized by directness or straightforwardness, and is called deductive thinking or general-particular thinking. English writing is very direct and formulaic. Writers should first clearly identify the topic or goal of an article and then support their argument with specific examples (Nunan, 2001: p. 297). Westerners express their opinions directly, whereas the Chinese do so in a round-about way. The following pairs of sentences illustrate this point:

(a) Our country is still in the stage of development, so we need to work hard to make our country more developed, and we should be thrifty at the same time.

(b) We should work hard to make our country more developed, and we should be thrifty at the same time because our country is still in the stage of development.

(a) gives an explanation first and then states an opinion, (b) states the opinion first and then gives the explanation. The difference in order has to do with the different thought patterns of Chinese and westerners. English speakers are explicit in their way of thinking and speaking, first making their positions clear or expressing their opinions, and then giving descriptions or coming up with arguments or facts, whereas speakers of Chinese do it the other way around. Although there is nothing

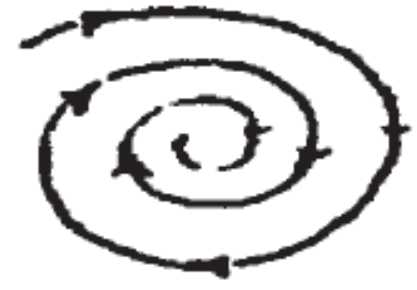

Chinese Circular Thinking

Figure 1.

Chinese and western thought patterns. ungrammatical in (a), the indirect way of expressing their viewpoints preferred by the Chinese students suggests the transfer of their L1 rhetorical structure as influenced by their thought patterns.

Another difference between the thought patterns of Chinese and westerners is that Chinese prefer subjective thinking, whereas westerners prefer objective thinking (Bao, 2001: pp. 30-32; Lian, 2002: pp. 40-48). This is reflected in language by animate subjects, especially human nouns, being used much more frequently in Chinese, whereas inanimate subjects, such as material objects and abstract concepts, are frequently used as subjects in English sentences. The following example illustrates this point:

(a) I suddenly got a good idea.

(b) A good idea suddenly occurred to (struck) me.

The abstract concept "a good idea" in (b) is used to replace the animate subject "I" for the sake of emphasizing the object because an "impersonal subject is often used as subject in English whereas personal subject is often used as subject in Chinese” (Liu, 2006: p. 498).

The main cause for producing the "a" sentences is that students write in English but still think in Chinese, which is difficult for them to identify because this way of thinking is deeply rooted in their patterns of thinking. The interviews with the students in this study showed that the students' L2 writing process is a bilingual event (i.e., L2 writers have both L1 and L2 at their disposal when they write in L2). The proportion of L1 thinking decreased with the writer's L2 development, which is consistent with the findings of others (Uzawa \& Cumming, 1989; Kobayashi \& Rinnert, 1992; Whalen \& Menard, 1995; Wang \& Wen, 2002). It also showed that it is more difficult for students to think in English with respect to the interpretation of the writing topic, the pre-writing thinking and writing process regulation, and it is comparatively less difficult for them to think in English in actual writing and outline writing.

It is understandable that Chinese college students rely on Chinese when their English is insufficient, and that they have not formed the habit of thinking in English. Krashen \& Terrell (1983) claim that reliance on the mother language is a productive strategy of learners because they are inadequately equipped with knowledge of the target language (p. 148). To avoid Chinglish caused by influence of the Chinese thought patterns, students should improve their English and at the same time adjust their ways of thinking from Chinese to English. The adjustment is a step-by-step process and it can-not be achieved overnight. Perseverance in both improving one's English and adjusting one's mode of thinking is the key to producing authentic English.

A good way for Chinese students to adjust their ways of thinking is for them to try to practice thinking and talking in English as much as they can. Teachers can set aside some time in class to involve students in activities such as "brain storming” to stimulate students' thinking in English (to be discussed later). Students should be encouraged to think and talk in English whenever they feel like saying something. Making friends with native English speakers and going to English corners are also good ways for students to adjust their ways of thinking from Chinese to English. English corners in China are on-campus sites for people to practice their English by communicating in English. Students can practice thinking in English in such an immersive environment. According to Long's (1996) Interaction Hypothesis, the interaction between native and 
non-native speakers makes the greatest contributions to L2 acquisition because it provides a plethora of opportunities for negotiation of meaning and form. Although Long's Interaction Hypothesis applies mostly to spoken English, it seems that once students' ways of thinking become more English-oriented by interacting with native English speakers, this orientation will naturally transfer to writing. Writing journals or diaries in English is also beneficial. When students practice thinking in English for a considerably long period of time, they may unconsciously and gradually form the habit of thinking in English when they need to write.

Other causes of Chinese college students' production of Chinglish include inadequate exposure to authentic English and insufficient practice in English writing.

\section{Inadequate Exposure and Practice}

Krashen's (1985) Comprehensible Input Hypothesis claims that learners need to receive adequate comprehensible input in order to move along the development continuum. The more competent learners are in the second language, the less likely that mother language transfer will occur (Xu, 2006: p. 32). In other words, inadequate exposure to authentic English or insufficient English competence is another cause of Chinglish.

Inadequate exposure to authentic English results in redundancy, improper word choice, collocation, and rhetoric, and inflexibility in expression.

\section{Improper Word Choice and Redundancy}

Improper word choice and redundancy in the students' writings analyzed in this part mainly stem from lexical transfer from Chinese language. The "a" sentences below show improper word choice or redundancy; the "b" sentences are their more idiomatic or succinct counterparts:

(a) Smoking is harmful to your body.

(b) Smoking is harmful to your health.

In (a), the use of "body" is a direct translation from Chinese. According to the componential analysis used in Yang's (2004) book, "body" and "health" bear different meanings in English: whereas "body" refers to "the whole physical structure of a person or animal as opposed to the mind or soul", "health" means "the condition of the body with regard to disease." The crosslinguistic difference here is one of lexical-semantic domain: the semantic domain of the Chinese term "shenti" (in pinyin) covers those of both "body" and "health", whereas in English, "body" and "health" have different semantic domains. As Chen (1981) points out, "in the choice of an English equivalent for a Chinese word, we must look beyond the word itself and consider its connection with other word or words in the sentence" (pp. 21-22). The problem with (a), then, is that the writer translated a Chinese lexeme with a broader semantic domain into English, where the context required a related term with a narrower semantic domain. Students should consider the meaning and function of the intended message and strive for an equivalent pragmatic effect when it comes to the choice of a proper word.

(a) My tire of the wheel became broken on the way.

(b) I got a flat tire on the way.

In (a), "of the wheel" is redundant. According to the dictionary (Longman Dictionary of Contemporary English, 1998: p. 1672), "tire" is glossed as "a thick band or rubber... that fits round the outside edge of a wheel...". The meaning "of the wheel" is already included in the word "tire". "Vigorous writ- ing is concise. A sentence should contain no unnecessary words...” (Pinkham, 1998: p. 1). Students should be alert to redundancy in their writings.

\section{Improper Collocations}

Experts in the contrastive study of collocations report that learners seem to rely on a "hypothesis of transferability," whereby the majority of collocation errors found in L2 students' writing can be traced to L1 influence. Example is given in the following pairs of sentences.

Facing various kinds of pressure, college students shouldn't force themselves to do things out of their ability.

Facing various kinds of pressure, college students shouldn't exert themselves beyond their ability. Facing various kinds of pressure, college students shouldn't push themselves too hard.

(a) shows negative transfer from Chinese to English. The phrase "force oneself to do things out of one's ability" is a literal translation from Chinese, whereas "go/exert oneself beyond one's ability" or "push oneself too hard" are idiomatic expressions.

Some students revealed that they learn English vocabulary by citing wordlist books or referring to bilingual electronic-dictionaries, a practice identified as the cause of some Chinesecharacteristic phrases at the expense of idiomatic collocations. Some Chinese students learn English vocabulary and expressions by referring to bilingual lists of words in wordlist books or bilingual electronic-dictionaries in which word translations are offered with little or no explanation about their usage. As a result, students transfer meanings from their native language to English mechanically. However, their limited knowledge of the usage of the words and expressions often causes them to literally translate their characteristically Chinese expressions into English. Problematic collocations such as "make success" and "do ... out of one's ability" are quite common in students' writings. (The more appropriate expressions are "achieve/gain success" and "go /exert oneself beyond one's ability”.) Usually the meaning of one word has great bearing on the words associated with it. If the collocation associated with the word is not learned as part of a student's knowledge of L2 vocabulary and collocations, the resulting problems will immediately mark his/her writings as Chinglish. Context is important in enhancing students' knowledge concerning vocabulary and collocation. Students should do extensive reading and listening so as to acquire more useful vocabulary and collocations.

\section{Improper Rhetoric}

Language and culture are closely related with each other. Neither can be separated from the other. Deng (1983) explains the relationship between language and culture as follows: "Language is a part of culture and plays a very important role in it.... Without language, culture would not be possible. On the other hand, language is influenced and shaped by culture, it reflects culture. In the broadest sense, language is the symbolic representation of a people, and it comprises their historical and cultural backgrounds as well as their approaches to life and their ways of living and thinking.” (p. 3)

The following pair of sentences illustrate the cultural influence of Chinese college students in their ESL writings.

(a) Li Ming was like a wet chicken when he came home.

(b) Li Ming was like a drowned cat when he got home.

In (a), the Chinese metaphor compares a soaked person to "a 
wet chicken"; however the idiomatic expression in English is "a drowned cat". (a) is grammatically correct, but not target language-like by not being idiomatic. The lack of cultural knowledge in English-speaking countries gives rise to Chinglish in (a).

Some expressions are specific to certain cultures. Expressions convey the intended message only in terms of the cultures in which they function. Therefore, students' writings in English need to show awareness of the cultures associated with the target language in order to convey meaning successfully.

Some idioms are acquired gradually, day by day. How can students know that "a drowned cat" refers to "a wet and drenched person", and that "a piece of cake" means "an easy job" if they have never encountered them? Lack of exposure is a big problem for students learning a language in a non-authentic environment. A good way to approach this problem is to increase students' exposure to authentic English and to encourage daily learning.

\section{Inflexibility in Expression}

Inflexibility is meant here to indicate a rigidity of perspective or a lack of change with respect to habitual thought patterns. The following examples show students' inflexibility of expression:

(a) The government has made great efforts to help laid-off workers to get a job again.

(b) Great efforts have been made (by government) for the reemployment of the laid-off workers.

Sentence (a) shows Chinese students' marked preference for the active voice, though the passive is more appropriate for the written English example.

(a) When you don't feel well, you can go out travelling.

(b) Travel can make you fresh and delighted.

(a) shows Chinese students' preference for the personal subject "you" when the use of a non-personal subject "travel" makes the English sentence neat and expressive.

A change of perspectives in expressing ideas from Chinese into English will help reduce Chinglish.

The cause of Chinglish here is due to students' inadequate exposure to authentic English. Students are more likely to use inanimate subjects and the passive voice if they encounter them frequently in their listening and reading.

Increasing exposure to authentic English is the key to attaining proficiency in English and prevent students from using Chinglish. Extensive reading and listening is the most helpful way for Chinese students to increase the input of English language and culture. Through reading, students get to know ways of writing in English and English syntax. Extensive reading and listening leads to multiple encounters with idiomatic usage of words and expressions in a variety of meaningful contexts. Only after seeing or hearing words and expressions used in different situations can students become certain of their idiomatic use.

Cognitive psycholinguistic theory claims that "a foreign language learner's competence in using the language is actually the combination of the learner's receptive skills (listening and reading) and productive skills (speaking and writing). As language acquisition is in fact a process in which input and output affect each other, different language skills are best assumed to develop simultaneously and complement each other through the process" (Stern, 1983: p. 399). It is far from enough for Chinese students who want to write a good composition with less
Chinglish to simply increase exposure to authentic English. Input alone is not enough, writing practice is of vital importance as well. Swain's (1985) Output Hypothesis argues that output production of the targeted form in addition to input is necessary for learners' internalization of the language.

Output production forces learners to recognize problems in their interlanguage, subsequently prompting them to seek solutions to these problems (Izumi \& Bigelow, 2000). Song and Suh (2008) claim that output production relates directly to Schmidt's (1990) Noticing Hypothesis, in that output often leads to noticing of nontarget-like expressions and overall problems in the interlanguage. Input needs to be coupled with output and the awareness of inappropriate usage in order to transfer input into intake and produce more target language-like English.

Teaching writing as a procedure is a practical way for students to write well and reduce Chinglish. The procedures can be grouped into three steps: preparation, writing and checking. Thinking and discussing in the preparation period is very important. Students' discussion about the topic at the pre-writing stage in groups or with the whole class is a good strategy to involve students in talking about a topic. As a warm up activity, brainstorming can take the form of oral discussion, helping students to think in English by simply focusing on the topic "in a stream-of-consciousness fashion” (Clausen, 1987: p. 7). Proofreading is a necessary step for discerning imperfection in their writings. It is a good way for students to check their writings for each other and exchange their viewpoints about their writings. They can find something inappropriate for others and help them to correct it. A lecture about Chinglish can bring the problem to students' full attention. It is only when students have "noticed the gap" between their nontarget-like expressions and those of more target-like ones that they can learn the features of the target language. Analyzing typical example of Chinglish can remind students to be aware of it and try to avoid it. Discussion between the teacher and students about certain problems a number of students share in their writings is an effective form of corrective feedback. For example, the following sentences are prevalent in students' writings:

(1) a) Curiosity made me want to open the box.

(2) a) The teacher's encouragement made me want to do better in my study.

Chinese students tend to write the above sentences because the causative structure is very common in Chinese. The teacher should help students realize that ideas can be carried across in more expressive ways than the Chinese "make somebody do something" structure and ask them to convey the meaning in alternative ways. The teacher can offer such options as:

(1) b) Curiosity drove me to open the box.

(2) b) The teacher's encouragement inspired me to do better in my study.

It is better to offer balanced feedback because the teacher's constant reminding students of Chinglish in their writings may weaken their confidence. Commenting on some excellent points in students' writings can help students gain confidence in improving their writings. Recommending well-written essays for students to read and imitate can also help students to write well.

\section{Conclusion}

Chinglish is produced by Chinese students influenced by Chinese language, culture and thought patterns. Chinglish is 
mainly caused by syntactic transfer from Chinese, the influence of Chinese thought patterns, inadequate exposure to authentic English and insufficient practice in English writing. The interviews with the students in this study showed that the students' L2 writing process is a bilingual event. The proportion of L1 thinking decreased with the writer's L2 development. It also showed that it is more difficult for students to think in English with respect to the interpretation of the writing topic, the pre-writing thinking and writing process regulation, and it is comparatively less difficult for them to think in English in actual writing and outline writing. Therefore, the ultimate solution for decreasing Chinglish in students' writings is to improve their English competence, thereby achieving proficiency in English. Chinese college students' production of Chinglish can be reduced if they are made conscious of the linguistic and cultural distinctions between English and Chinese, and are exposed to authentic English as much as possible, both to develop their knowledge of English language, society, and culture, and gradually adjusting their Chinese thought patterns to English ones. Practice writing as a procedure is also helpful in overcoming Chinglish.

This paper provides valuable information concerning the causes of and remedies for Chinglish in Chinese college students' English writings. It sheds new light on the study of Chinglish by adopting the method of corpus analysis and by making practical suggestions about enhancing English syntax and adjusting students' ways of thinking, and teaching writing as a procedure.

\section{Acknowledgements}

Special thanks should go to Dr Cheng Luo from Brock University in Canada and Dr Monro, an American professor who presently works at Wuhan University, for their support and valuable suggestions on my paper.

Heartfelt thanks should be extended to the students in Wuhan University for their cooperation and contribution.

\section{REFERENCES}

Bao, H. (2001). Cultural context and translation. Beijing: Foreign Language Teaching and Research Press.

Chen, Z. (1981). On problems of translation-A series of talks given at the institute of journalism. Beijing: Foreign Language Teaching and Research Press.

Clausen, M. (1987). Concise process handbook. New York: McGrawHill.

Cook,V. (1991). Second language learning and language teaching. London, UK: Edward Arnold.

Deng, Y. (1983). Language and culture. Beijing: Foreign Language Teaching and Research Press.

Deng, Y., \& Liu, Y. (2001). Language and culture-A contrastive study of English and Chinese language and culture. Beijing: Foreign Language Teaching and Research Press.

Ellis, R. (1985). Understanding second language acquisition. Oxford: Oxford University Press.

Ellis, R. (2000). Second language acquisition. Shanghai: Shanghai Foreign Language Research Press.

Izumi, S., \& Bigelow, M. (2000). Does output promote noticing and second language acquisition? TESOL Quarterly, 34, 239-278.

doi:10.2307/3587952

Jia, Yu. (1997). Cross-cultural communication. Shanghai: Shanghai Foreign Language Education Press.

Klein, W. (1986). Second language acquisition. Cambridge: Cambridge
University Press.

Kobayash, H., \& Rinnert, C. (1992). Effects of first language on second language writing: Translation versus direct composition. Language Learning, 42, 183-215. doi:10.1111/j.1467-1770.1992.tb00707.x

Krashen, S., \& Terrell, T. (1983). The natural approach. Oxford: Pergamoon/Alemany Press.

Krashen, S. (1985). The input hypothesis: Issues and implications. London, UK: Longman Publishing Press.

Li, J. (2007). Negative language transfer in college English writing by Chinese students: Problems and strategies. CELEA Journal, 2, 88103.

Lian, Sh. (1993). A contrastive study of English and Chinese. Beijing: Higher Education Press.

Lian, Sh. (2002). On the Chinese and western thinking mode. Foreign Language and Teaching, 2, 40-48.

Liu, M. (2006). Comparison of English and Chinese and translation. Beijing: China Translation Publishing Press.

Long, M. (1996). The role of the linguistic environment in second language acquisition. In W. C. Ritchie, \& T. K. Bhatia (Eds.), Handbook of second language acquisition (pp. 413-468). San Diego, CA: Academic Press.

Chen, F. K. (1998). Longman dictionary of contemporary English (English-Chinese). Beijing: Commercial Press.

Nunan, D. (2001). Second language teaching and learning. Beijing: Foreign Language Teaching and Research Press.

Odlin, T. (2001). Language transfer-Cross linguistic influence in language learning. Shanghai: Shanghai Foreign Language Education Press.

Pinkham, J. (1998). The translator's guide to Chinglish. Beijing: Foreign Language Teaching and Research Press.

Schmidt, R. (1990). The role of consciousness in second language learning. Applied Linguistics, 11, 129-158. doi:10.1093/applin/11.2.129

Song, M., \& Suh, B. (2008). The effects of output task types on noticing and learning of the English past counterfactual conditional. System, 36, 295-312. doi:10.1016/j.system.2007.09.006

Spada, N., \& Lightbrown, P. (2008). Form-focused instruction: Isolated or integrated? TESOL Quarterly, 42, 181-207.

Spolsky, B. (2000). Conditions for second language learning. Shanghai: Shanghai Foreign Language Education Press.

Stern,H. (1983). Foundamental concepts of language teaching. Oxford: Oxford University Press.

Swain, M. (1985). Communicative competence: Some roles of comprehensible input and comprehensible output in its development. In S. Gass, \& C. Madden (Eds.), Input in second language acquisition (pp. 235-253). Rowley, MA: Newbury House.

Uzawa, K., \& Cumming, A. (1989). Writing strategies in Japanese as a foreign language: Lowering or keeping up the standards. The Canadian Modern Language Review, 46, 178-194.

Wang, W., \& Wen, Q. (2002) Chinese thinking mode and second language writing-A study on the college students' English writing process. Journal of PLA University of Foreign Languages, 4, 64-76.

Whalen, K., \& Menard, N. (1995). L1 and L2 writers' strategic and linguistic knowledge: A model of multiple-level discourse processing. Language Learning, 44, 381-418. doi:10.1111/j.1467-1770.1995.tb00447.x

Xiao, A., \& Li, J. (2007). A course in English-Chinese translation. Chongqing: Chongqing University Press.

$\mathrm{Xu}, \mathrm{R}$. (2006). The markedness of not...until and transfer]. Journal of Sichuan College of Education, 11, 30-32.

Yang, X. (2004). Errors of innovativeness. Wuhan: Huazhong University of Science and Technology Publishing Press.

$\mathrm{Yu}, \mathrm{L}$. (2004). Language transfer and second language acquisitionReview, reflection and research. Shanghai: Shanghai Foreign Language Education Press.

Zhang, G. (2004). Recognize the differences and get the semantic emphasis-The most efficient way to avoid Chinglish. Journal of Tianjin Foreign Studies University, 4, 58-60. 


\section{Appendix 1. Questionire of Percentage of Thoughts in English among Students with Different}

\section{Placement Test Scores}

1. Percentage of thoughts in English in interpreting the writing topic

$\begin{array}{lllll}\text { A. } 0 \%-20 \% & \text { B. } 21 \%-40 \% & \text { C. } 41 \%-60 \% & \text { D. } 61 \%-80 \% & \text { E. } 81 \%-100 \%\end{array}$

2. Percentage of thoughts in English in pre-writing thinking

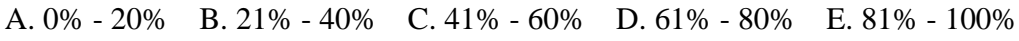
3. Percentage of thoughts in English in outline writing

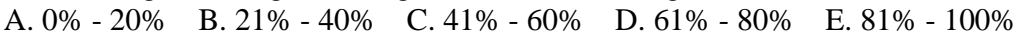
4. Percentage of thoughts in English in actual writing

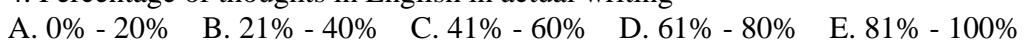
5. Percentage of thoughts in English in writing process regulation

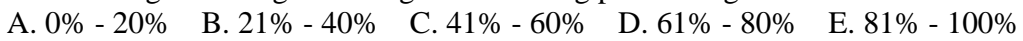

